\title{
Development of Digital Personnel by Modernizing the System of Education
}

\author{
Julia Gnezdova \\ Smolensk State University \\ Smolensk, Russia \\ E-mail: Iuliy_67@mail.ru
}

\author{
Olga Zvyagintseva \\ Vladimir Legal Institute of Federal Service of Execution of \\ the Punishment \\ Vladimir, Russia \\ E-mail: olgavib55@mail.ru
}

\begin{abstract}
The paper gives an assessment of the development of digital economy through the system of education and personnel retraining, which should provide economy with specialists who meet the requirements of the digital age. The Institute of Education is undergoing significant changes. Countries that have managed to adapt their educational infrastructure to new needs will be able to significantly strengthen their economic positions in the transition to digital economy. According to the UNESCO report, about 150 million students in the world are now in the process of obtaining a diploma. The relevance of the study lies in the fact that the sphere of education is one of the key and most promising sites for global competition of states for economic power and political influence in the $21^{\text {st }}$ century. Carrying out work on improving the educational infrastructure, it is also necessary to create opportunities for self-realization of high-class specialists in Russia.
\end{abstract}

Keywords-education system; digital economy; digital personnel; modernization of education

\section{INTRODUCTION}

Digitalization transforms the social paradigm of people's lives. It opens unprecedented opportunities for acquiring new knowledge, expanding horizons, developing new professions and improving skills. There are new social elevators. Geographic horizons of opportunities are expanding. Thanks to more comfortable cities, efficient public institutions and affordable public services, the conditions of everyday life of citizens improve. States that are tuned to innovation and research, like a magnet, attract qualified personnel - a key resource of digital economies. More and more factors indicate that the time has come for a paradigm shift for the training system, including the education system. Universities, educational consortia and entire countries today are doing their best to attract international students. They are mobile young people (there are more than 5 million people in the world), possessing great abilities. The war for talent leads to a rapid differentiation of educational institutions. Today according to the Times Higher Education magazine, two Russian universities - the Moscow State University (MSU) and the St. Petersburg National Research University of Information Technologies, Mechanics and Optics (ITMO) are among the top 100 universities in the world in computer science [1-3]. However, according to some indicators, the
Russian education system lags far behind the countries digital leaders, which create the risks of lack of digital personnel in the future. Thus, the overall level of training of Russian schoolchildren is on the average for OECD countries, and in this respect, Russia is much inferior to the leading countries: Singapore, Japan, Estonia, Finland and a number of others, both in terms of average score and the proportion of students who received maximum estimates [24]. The same applies to universities: although the number of Russian educational institutions in the list of 980 best universities in the world, according to the Times Higher Education, doubled in the last year and reached 24, according to the total number of institutions on this list, Russia is significantly inferior to such digital leaders as the United States (148) and Great Britain (91), as well as such "catching up" countries as China (52) and Brazil (27) [3]. At the same time, not a single Russian university is included in the list of the top 100, while China has five universities in it.

\section{OBJECTIVES AND METHODS}

The purpose of the publication is to analyze the available scientific literature and the results of a study on development in the field of digital technologies and platforms that can have a significant positive impact on the labor market. They will facilitate the search for personnel, shorten the terms of job search, increase the productivity of employees, improve the situation with the involvement of personnel in the economy through remote workplaces and provide access to quality education. The state, business and educational institutions will require coordinated advance actions to prepare for future changes, as well as retraining and placement of the released personnel. The research used the following methods: analysis of official statistics, sociological research; method of document analysis.

Until now, the domestic labor market has remained virtually unchanged under the influence of digital technologies, reacting to economic crises not so much by shrinking jobs, but by a decline in the overall level of salaries. However, the accelerating digitalization of the economy confronts the sectors and the state and the education system with new tasks that they have not previously encountered. With further digital transformation of the economy, the introduction of automation, increased productivity and the 
replacement of physical channels with digital services, more jobs may be in danger of extinction. According to the Global Institute of McKinsey, by 2036, from 2 to $50 \%$ of work expressed in man-hours can be automated, and by 2066 this share can reach 46 to $99 \%$. Since it is easiest to automate those types of work that require the execution of predictable repetitive physical operations, as well as activities to collect and analyze information, this process first of all will concern jobs that require an average qualification.

\section{RESULTS AND DISCUSSION}

\section{A. Worldwide Trends in the Adaptation of the Education System to the Digital Economy}

For modern mankind it is much more important to receive new knowledge and skills, it is obvious for everyone who sets himself the task of speedy development of the digital economy. The development of digital technologies changes the ways in which knowledge is captured, transmitted and created, and skills are formed. In addition, digital technologies change the process of assessing and fixing achievements, the process of forming their own educational trajectory, processes in the management of educational institutions and so on. Digital technology makes it possible to individualize education without increasing costs for it. The growth of databases, individual profiles of students and teachers is a source of data for creating increasingly effective algorithms for designing individual educational trajectories, taking into account the increasing number of factors affecting the realization of the interests of all parties involved [4].

Governments and centers of innovation and development in France, the United States, Great Britain and other countries discuss various opportunities for mass retraining and adaptation of personnel to the digital economy. In Singapore, there is a decline in the level of the educational system, from which programming courses are taught, and startups appear everywhere to raise the digital literacy of schoolchildren and even preschool children. Stronger measures are also being taken to adapt the economy. Bill Gates offered to tax not only the physical workers, but also the robots that replaced them. No less brave idea - to introduce universal basic income - is not only widely discussed, but also in the form of an experiment already embodied in the Silicon Valley, the Netherlands, Canada and Finland.

The plan for the modernization of the German education system is called "School 4.0" (similar to the name "Industry $4.0 "$ ). The concept is based on the features of the fourth industrial revolution and the Internet of things. One of the most advanced countries in terms of the digital economy, in my opinion, is Singapore. First of all, is due to the significant involvement of the government in issues of digitalization of the economy. Information technologies are actively being introduced in all sectors, all public services are translated into electronic format education system of Singapore is actively using online training. Singapore was an example of successful interaction of the state, business and the education system to build a modern educational infrastructure aimed at training personnel who are free to focus on the labor market in the digital economy. The reform that began in the 1990s in the modernization of Singapore's school and university education has made it possible to increase the flexibility of the system as a whole and to revise the process of forming educational programs. With the launch of this reform, the Government of Singapore, with the participation of relevant ministries and business representatives, began to conduct regular activities to clarify the list of priority specialties and skill groups, depending on the expected future labor market needs.

The results of a study conducted in Australia in 2015 show that $60 \%$ of university students are trained in specialties that will be largely automated in the next 10-15 years [5]. If such professions as a programmer and a database developer became popular for a long time, then specialization in analyzing large data sets and protecting private data, digital marketing and promotion in social networks, the profession of a blogger and other specialties gained wide popularity only in recent years. The widespread use of online education systems enables employees to develop additional competencies necessary to form a career path in the digital age. The above properties of modern technologies will partially compensate for the effect of the release of personnel due to automation and will facilitate the employment of people whose jobs will be occupied by robots. Global education in the $21^{\text {st }}$ century is becoming a system for the exchange of competences.

\section{B. The Impact of the Digital Economy on Russian Education}

Today, Russian schools and higher education institutions are characterized by an obsolete subject-oriented education system and weak interaction with potential employers. In addition, despite the modernization of the material and technical base of educational institutions in recent years (connection to the Internet and computer equipment), digital technologies in the educational process are not used intensively. The methods, educational formats, educational programs used in the national education, approaches to interaction with potential employers require adaptation to the needs of the digital economy, so that the educational system can continue to prepare competitive personnel. This task should be considered as a priority, since the availability of a sufficient number of highly skilled 'digital' personnel is one of the conditions for the success of the deployment in Russia of new digital technologies, such as "Industry 4.0".

In the long term, the Russian education system at all levels needs a more extensive transformation based on such principles as lifelong learning (Lifelong Learning), the flexibility of educational trajectories and modularity of educational courses [6]. At the same time, it is necessary to focus on developing the personal, social skills and skills of the students in solving interdisciplinary tasks oriented to practice, as well as applying modern methods, formats and training tools, including digital educational tools and formats of remote education. It is also important to develop the interaction of educational and research organizations among themselves, with the business community and with state 
bodies in order to ensure the relevance and importance of educational programs and reduce the time of adaptation of the educational system to market requirements.

Today, instead of rigid prescribed and final trajectories, students need to build individual trajectories and become mobile by selecting courses and programs (both at all levels of formal education and in complementary education) that provides the opportunity for continuous updating of competencies [7]. At the same time, the rigid boundaries of the education system are eroding, as renewal of competencies can occur on the actual production of goods, knowledge and technology. The key factor is the independent work of students, and, consequently, their independent access to educational resources and technologies of self-education. For this, access to educational resources is necessary at all levels of the educational system, first of all in the form of public libraries of digital educational resources on the basis of domestic developments and localization of the best educational resources from around the world.

\section{CONCLUSION}

In recent years, the state has made efforts to overcome the backlog of the Russian education system from the countries - digital leaders. Digital technologies provide an opportunity to increase the motivation of students to acquire new knowledge and competences, provide greater geographical coverage, individual trajectory of education, including for children with disabilities, they create truly equal opportunities for all participants in the educational process. The main competence that needs to be developed is the ability to constantly learn, the willingness to constantly learn new knowledge about new emerging technologies. This is a key factor for successful professional growth in the modern digital world [8].

Today, large companies prefer to act for them. They create universities there are now more than four thousand of them all over the world. Some are moving to the ideology of project and problem-oriented learning, which allows not only to quickly teach employees, but also to solve strategic tasks. The most advanced managers are rebuilding the entire management system, relying on the model of self-learning organizations. They use the concept of 'implicit' knowledge - this is know-how and a set of professional practices that cannot always be formalized. Transfer of such knowledge occurs not in lectures or seminars, but in the process of mutual learning and interaction in the workplace. Teaching people to learn from each other is a strategically more accurate decision, but it requires abandoning the rigid vertical structure that is customary for most companies.

\section{REFERENCES}

[1] World University Rankings 2016-2017 / Times Higher Education. https://www.timeshighereducation.com/world-universityrankings/2017/worldranking\#!/page/0/length/25/sort_by/rank/sort_order/asc/cols/stats. [45]

[2] World University Rankings 2016-2017 / Times Higher Education. https://www.timeshighereducation.com/world-university- rankings/2017/worldranking\#!/page/0/length/25/sort_by/rank/sort_order/asc/cols/stats. [47]

[3] TIMSS - Trends in Mathematics and Science Study, International study on the evaluation of the quality of mathematical and natural science education, conducted by an international educational center IEA's TIMSS \&PIRLS (Boston, USA). TIMSS 2015 International Results Report / TIMSS \& PIRLS International Study Center. - 2015. -http://timssandpirls.bc.edu/timss2015/internationalresults/download-center/

[4] Kupriyanovsky V.P., etc. Digital economy - "Smart way to work" // International Journal of Open Information Technologies. 2016, Vol. 4, No. 2, pp. 26-33.World University Rankings 2016-2017 / Times Higher Education. - https://www.timeshighereducation.com/worlduniversity-rankings/2017/worldranking\#!/page/0/length/25/sort_by/rank/sort_order/asc/cols/stats. [45]

[5] World University Rankings 2016-2017 / Times Higher Education. https://www.timeshighereducation.com/world-universityrankings/2017/world-

ranking\#!/page/0/length/25/sort_by/rank/sort_order/asc/cols/stats. [45]

[6] Shmelkova L.V., Cadres for the digital economy: a look into the future / / Additional vocational education in the country and the world 2016, No. 8 (30), pp. 1-4. PISA 2015. PISA Results in Focus /. 2015. - http://www.oecd.org/pisa/pisa-2015-results-in-focus.pdf [46]

[7] Kupriyanovsky V.P., etc. Digital economy - "Smart way to work" // International Journal of Open Information Technologies. 2016, Vol. 4, No. 2, pp. 26-33.

[8] L. V. Shmelkova, Cadres for the digital economy: a look into the future / / Additional vocational education in the country and the world, 2016, No. 8 (30), pp. 1-4. PISA 2015. PISA Results in Focus /. 2015. - http://www.oecd.org/pisa/pisa-2015-results-in-focus.pdf [46 